Case Report

\title{
Safety of Sofosbuvir and Ribavirin Combination Therapy in a Patient Who Developed Anemia due to Ribavirin
}

\author{
Hirokazu Suii, Itaru Ozeki, Ryoji Tatsumi, Masakatsu Yamaguchi, Mutsuumi Kimura, \\ Tomohiro Arakawa, Tomoaki Nakajima, Yasuaki Kuwata, Takumi Ohmura, Shuhei Hige, \\ Yoshiyasu Karino, and Joji Toyota
}

Department of Hepatology, Sapporo Kosei General Hospital, 8-5 Kita Sanjo Higashi, Chuo-ku, Sapporo, Hokkaido 060-0003, Japan

Correspondence should be addressed to Hirokazu Suii; hrkz17@gmail.com

Received 1 September 2017; Revised 12 November 2017; Accepted 20 November 2017; Published 10 December 2017

Academic Editor: Mauro Vigano

Copyright (C) 2017 Hirokazu Suii et al. This is an open access article distributed under the Creative Commons Attribution License, which permits unrestricted use, distribution, and reproduction in any medium, provided the original work is properly cited.

Interferon (IFN) and ribavirin (RBV) combination therapy was previously the standard of care for treatment of hepatitis C virus (HCV) genotype 2 infection. But, it often induced hemolytic anemia. In 2014, sofosbuvir (SOF) was approved for the treatment of chronic HCV genotype 2 in Japan. SOF/RBV therapy is more effective against genotype 2 than IFN/RBV therapy. We report a case of a 74 -year-old woman with chronic HCV genotype $2 b$ infection. She received five treatments including RBV and IFN therapy before SOF was approved and all of them were ineffective. Therapies that included RBV induced severe anemia and led to discontinuation of treatment. With pegylated IFN/RBV therapy, the maximum change in hemoglobin (Hb) from baseline was $-3.7 \mathrm{~g} / \mathrm{dL}$. However, SOF/RBV therapy was effective and she achieved sustained virologic response (SVR) with a maximum change in $\mathrm{Hb}$ from baseline of only $-1.2 \mathrm{~g} / \mathrm{dL}$. We also found reticulocyte count was very low during treatment in this case and speculate it was one of the reasons that she developed hemolytic anemia with RBV. In conclusion, SOF/RBV therapy is effective and allowed the patient to achieve SVR. An SOF/RBV regimen is safe and effective for patients who have or are at risk of anemia induced by RBV.

\section{Introduction}

Chronic hepatitis C virus (HCV) infection is a cause of chronic liver disease and hepatocellular carcinoma $[1,2]$. Recently, most patients with HCV infection are treated with interferon-free direct-acting antiviral agents (DAAs). Previously, ribavirin (RBV) was commonly used in combination with pegylated interferon (Peg-IFN) for treatment of HCV infection; however it often induced severe hemolytic anemia and patients tended to discontinue treatment even with a reduction of RBV dose. It has been reported that clinical risk factors for severe RBV-induced anemia include impaired renal function, older age, high dose per body weight of RBV, and female sex [3]. Here, we report a case of HCV genotype 2 infection in a patient who previously had severe anemia with IFN/RBV combination therapy. Despite a low reticulocyte count, she was able to achieve sustained virologic response (SVR) with the combination of sofosbuvir (SOF) and RBV.

\section{Case Report}

We present a case of a 74-year-old woman. She had a history of surgery to resect a pelvic tumor 30 years ago, which caused massive bleeding and required blood transfusion. One month after surgery, she was hospitalized for 10 months owing to posttransfusion hepatitis. She was subsequently diagnosed with HCV infection. In December of 2006, she visited our hospital for treatment of chronic hepatitis C. Laboratory examination showed her HCV genotype was $2 \mathrm{~b}$ and pretreatment viral load was $1500 \mathrm{KIU} / \mathrm{mL}(6.17 \log \mathrm{IU} / \mathrm{mL})$. Her IL28B genotype showed a single-nucleotide polymorphism (SNP) TT (rs8099917) as major homozygous and the ITPA genotype showed SNP CA (rs7270101) as minor allele heterozygous. The clinical treatment progress is as follows (Figures 1 and 2). Initial treatment with Peg-IFNalpha $2 \mathrm{~b} 80 \mu \mathrm{g} /$ week and RBV $400 \mathrm{mg} /$ day was started in our hospital in March of 2007. After 10 weeks of therapy with this regimen, she developed severe hemolytic anemia. 


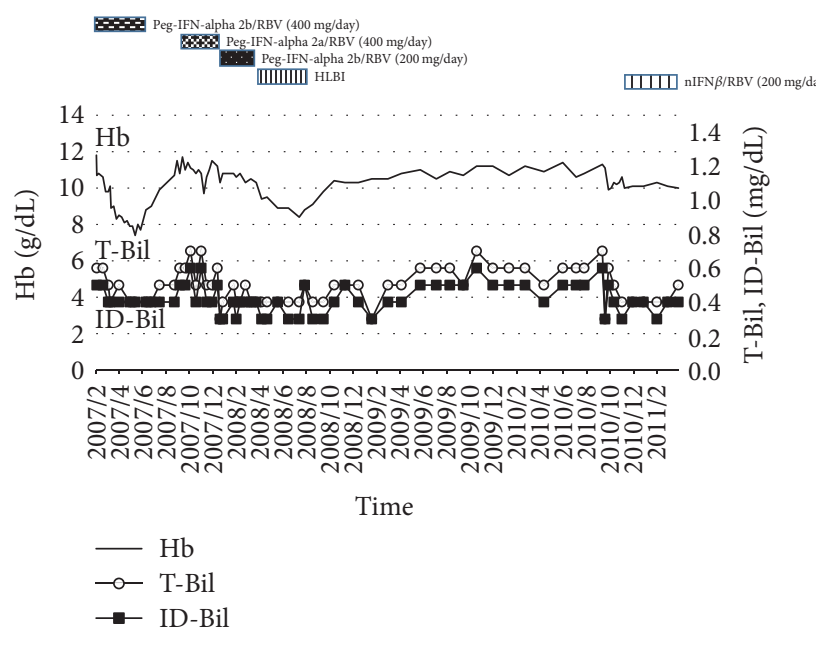

Figure 1: Clinical course of patient (Hb, T-Bil, and ID-Bil). T-Bil: total bilirubin; ID-Bil: indirect bilirubin.

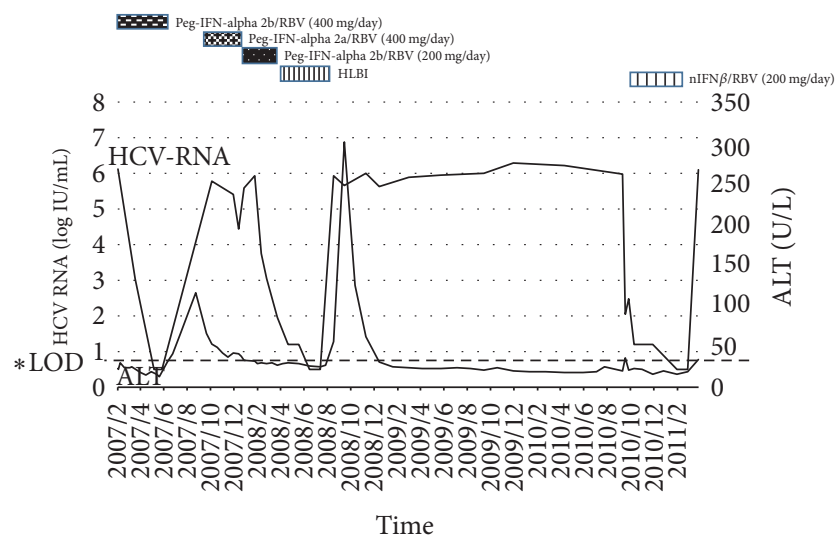

Figure 2: Clinical course of patient (ALT and HCV RNA). * Limit of detection (LOD).

Her hemoglobin $(\mathrm{Hb})$ level decreased from 12.0 to $8.1 \mathrm{~g} / \mathrm{dL}$, requiring discontinuation of treatment.

Secondly, she received Peg-IFN-alpha 2a $80 \mu \mathrm{g} /$ week with RBV (400 mg/day), but the treatment was not effective and resulted in virological breakthrough. Treatment with the same dose of Peg-IFN-alpha $2 \mathrm{~b}$ and a $50 \%$ dose reduction of RBV ( $200 \mathrm{mg} /$ day) was then started for 12 weeks (since November 2007). Due to the low dose of RBV, the viral load did not change and SVR could not be achieved. Fourthly, the administration of long-term low dose human lymphoblastoid interferon (HLBI) $6 \mathrm{MU} /$ day was started (since February 2008). After 20 weeks of therapy, a treatment-induced stomatitis developed and this treatment was discontinued. After the fourth treatment, she did not receive antiviral treatment for two years. In October 2010, treatment with nIFN $\beta$ $6 \mathrm{MU} /$ day and RBV $200 \mathrm{mg} /$ day was started. The hemoglobin level was not reduced too much because of the low dose of RBV. She achieved an undetectable HCV RNA status with this treatment, but HCV RNA relapsed 4 months after the completion of treatment. In 2014, SOF was approved for the treatment of genotype 2 chronic hepatitis $\mathrm{C}$ in Japan. Starting
TABLE 1: Laboratory results at the start of SOF/RBV combination therapy $(2015 / 9)$.

\begin{tabular}{|c|c|c|}
\hline \multicolumn{3}{|l|}{$C B C$} \\
\hline WBC & 3.4 & $\times 10^{3} / \mu \mathrm{L}$ \\
\hline $\mathrm{RBC}$ & 3.3 & $\times 10^{6} / \mu \mathrm{L}$ \\
\hline $\mathrm{Hb}$ & 10.4 & $\mathrm{~g} / \mathrm{dL}$ \\
\hline Hct & 29.9 & $\%$ \\
\hline $\mathrm{MCV}$ & 90.6 & $\mathrm{fL}$ \\
\hline Plt & 159 & $\times 10^{3} / \mu \mathrm{L}$ \\
\hline Reticulocyte & 1.37 & $\%$ \\
\hline \multicolumn{3}{|l|}{ Coagulation } \\
\hline $\mathrm{PT}$ & 81 & $\%$ \\
\hline \multicolumn{3}{|l|}{ Tumor marker } \\
\hline AFP & 3.6 & $\mathrm{ng} / \mathrm{mL}$ \\
\hline PIVKA-II & 18 & $\mathrm{mAU} / \mathrm{mL}$ \\
\hline \multicolumn{3}{|l|}{ HCV viral marker } \\
\hline HCV RNA & 6.14 & $\log \mathrm{IU} / \mathrm{mL}$ \\
\hline HCV genotype & $2 \mathrm{~b}$ & \\
\hline \multicolumn{3}{|l|}{ Biochemistry } \\
\hline $\mathrm{TP}$ & 7.2 & $\mathrm{~g} / \mathrm{dL}$ \\
\hline Alb & 4.2 & $\mathrm{~g} / \mathrm{dL}$ \\
\hline Ferritin & 98 & $\mathrm{ng} / \mathrm{ml}$ \\
\hline T-Bil & 0.9 & $\mathrm{mg} / \mathrm{dL}$ \\
\hline D-Bil & 0.1 & $\mathrm{U} / \mathrm{L}$ \\
\hline ID-Bil & 0.8 & $\mathrm{U} / \mathrm{L}$ \\
\hline AST & 37 & $\mathrm{U} / \mathrm{L}$ \\
\hline ALT & 26 & $\mathrm{U} / \mathrm{L}$ \\
\hline LDH & 227 & $\mathrm{U} / \mathrm{L}$ \\
\hline ALP & 134 & $\mathrm{U} / \mathrm{L}$ \\
\hline$\gamma$-GTP & 13 & $\mathrm{U} / \mathrm{L}$ \\
\hline BUN & 10.9 & $\mathrm{mg} / \mathrm{dL}$ \\
\hline $\mathrm{Cr}$ & 0.63 & $\mathrm{mg} / \mathrm{dL}$ \\
\hline eGFR & 69.1 & $\mathrm{ml} / \mathrm{min} / 1.73 \mathrm{~m}^{2}$ \\
\hline T-chol & 199 & $\mathrm{mg} / \mathrm{dL}$ \\
\hline $\begin{array}{l}\text { IL-28B genotype } \\
\text { (rs8099917) }\end{array}$ & TT & \\
\hline ITPA & $\mathrm{C} / \mathrm{A}$ & \\
\hline \multicolumn{3}{|l|}{ (rs7270101) } \\
\hline FIB-4 index & 3.38 & \\
\hline Fibro scan ${ }^{*}$ & 4.3 & Kpa (F0 level) \\
\hline $\mathrm{CAP}^{* *}$ & 206 & $\mathrm{~dB} / \mathrm{m}$ (S0 level) \\
\hline Height & 148 & $\mathrm{~cm}$ \\
\hline Weight & 49.8 & $\mathrm{~kg}$ \\
\hline
\end{tabular}

in September 2015, she was treated with SOF $400 \mathrm{mg} / \mathrm{day}$ and RBV $600 \mathrm{mg} /$ day for 12 weeks. This RBV initial dose was the highest dose of her previous treatments. Laboratory results at the start of SOF/RBV combination therapy are shown in Table 1. Since her Hb level decreased gradually, the RBV dose was reduced from 600 to $400 \mathrm{mg}$ /day at 4 weeks (Figure 3). And, in spite of anemia, the reticulocyte count 


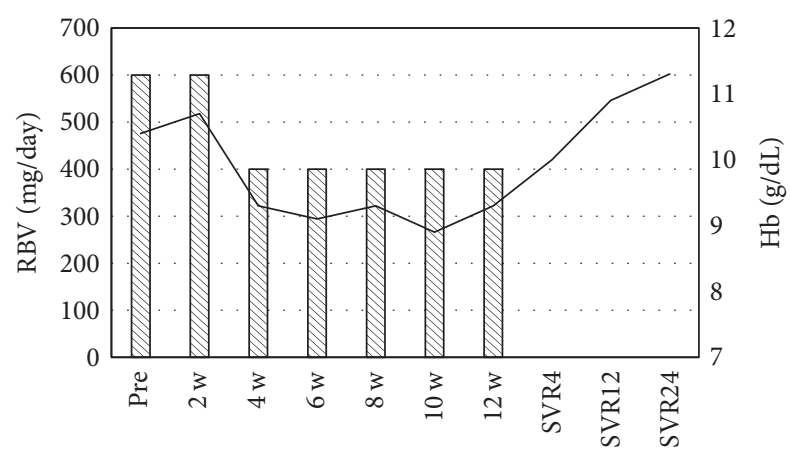

Time (weeks)

Figure 3: The variation of hemoglobin value with SOF and RBV combination therapy. Sofosbuvir dose was $400 \mathrm{mg} /$ day.

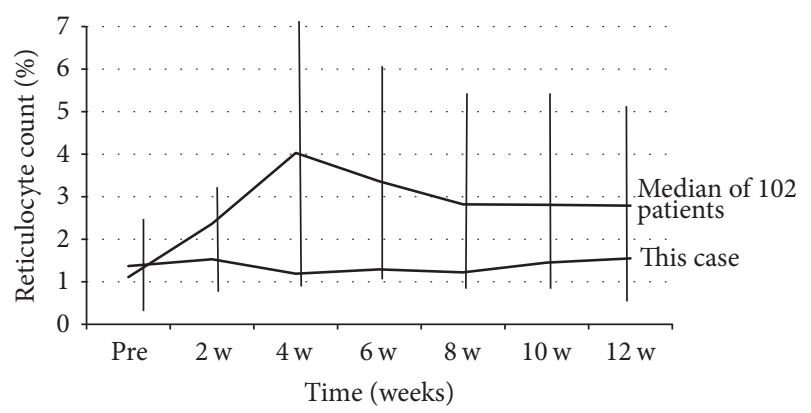

FIGURE 4: The variation of reticulocyte count during treatment with IFN and RBV combination therapy in this case and median of another 102 patients treated by our hospital.

did not respond to the stimuli; it was very low during this treatment in this case (Figure 4).

Although SOF/RBV combination therapy tended to induce hemolytic anemia like previous therapies, she completed 12 weeks of SOF/RBV therapy and finally achieved SVR.

Written informed consent was obtained from the patient for publication of this case report.

\section{Discussion}

IFN and RBV combination therapy was previously the standard of care for treatment of genotype $2 \mathrm{HCV}$ infection [4]. IFN therapy is more effective against genotype 2 than genotype $1[5,6]$. Approximately $80 \%$ of genotype 2 patients who received 24-week Peg-IFN/RBV combination therapy achieved SVR [6-8]. However, RBV often induces severe hemolytic anemia, and IFN can induce side effects such as granulocytopenia and thrombocytopenia and neuropsychiatric effects like depression [9]. These adverse effects are the reason why most patients discontinue treatment of $\mathrm{HCV}$ infection with IFN/RBV combination therapy; lack of treatment results in the inability to achieve an SVR. Many patients waited until DAAs were approved. In this case, the patient discontinued multiple previous therapies because of severe hemolytic anemia with RBV. As an older, female patient, the patient did have risk factors for severe RBV-induced anemia. However, her CA ITPA genotype (minor allele heterozygous) is less likely to be affected by hemolytic anemia than the CC ITPA genotype (major homozygous) [10]. She also had normal renal function. In spite of generally favorable treatment conditions, she could not achieve SVR. The approval of SOF in Japan allowed the patient to achieve SVR with SOF/RBV combination therapy. In a Japanese phase 3 trial, $97 \%$ of genotype 2 patients achieved SVR12 and experienced a mean change in $\mathrm{Hb}$ from baseline to week 12 of treatment of only $-1.7 \mathrm{~g} / \mathrm{dL}$ [11]. In this case, the maximum change in $\mathrm{Hb}$ from baseline was only $-1.2 \mathrm{~g} / \mathrm{dL}$ (Figure 3 ) whereas, with previous IFN/RBV combination therapy, the maximum $\mathrm{Hb}$ decrease from baseline was $-3.7 \mathrm{~g} / \mathrm{dL}$.

In addition, it is notable that the reticulocyte count was very low during treatment with SOF/RBV in this case (Figure 4). It has been reported that reticulocyte count tends to increase from baseline within the first three weeks in response to anemia after RBV therapy-induced hemolytic anemia [12]. In our hospital, the median variation of reticulocyte count in 102 patients who received SOF/RBV combination therapy was $4.03 \%$ at four weeks. All 102 patients had an increase of reticulocyte counts during the first four weeks of therapy. However, this case did not show an increase of reticulocyte count during treatment. This is possibly due to prior bone marrow suppression. This mechanism is not well known. From this case, we can conclude that there is a value in using SOF/RBV combination therapy for the failed cases of therapies including IFN and RBV. Of course, for cases where the hemoglobin value does not rise above $12 \mathrm{~g} / \mathrm{dL}$, other treatment options should be considered.

In summary, SOF/RBV combination therapy is an appropriate and effective treatment for patients with chronic $\mathrm{HCV}$ genotype 2 infection, especially patients who could not achieve SVR due to severe hemolytic anemia or other side effects caused by RBV and IFN.

\section{Conflicts of Interest}

The authors declare that there are no conflicts of interest regarding the publication of this paper.

\section{References}

[1] S. Takano, O. Yokosuka, F. Imazeki, M. Tagawa, and M. Omata, "Incidence of hepatocellular carcinoma in chronic Hepatitis B and C: a prospective study of 251 patients," Hepatology, vol. 21, no. 3, pp. 650-655, 1995.

[2] Y. Shiratori, S. Shiina, M. Imamura et al., "Characteristic difference of hepatocellular carcinoma between hepatitis B- and C- viral infection in Japan," Hepatology, vol. 22, no. 4, pp. 10271033, 1995.

[3] S. Russmann, I. Grattagliano, P. Portincasa, V. O. Palmieri, and G. Palasciano, "Ribavirin-induced anemia: mechanisms, risk factors and related targets for future research," Current Medicinal Chemistry, vol. 13, no. 27, pp. 3351-3357, 2006.

[4] H. Kumada, T. Okanoue, M. Onji et al., "Guidelines for the treatment of chronic hepatitis and cirrhosis due to hepatitis $\mathrm{C}$ 
virus infection for the fiscal year 2008 in Japan," Hepatology Research, vol. 40, no. 1, pp. 8-13, 2010.

[5] M. Martinot-Peignoux, P. Marcellin, M. Pouteau et al., "Pretreatment serum hepatitis $C$ virus RNA levels and hepatitis $C$ virus genotype are the main and independent prognostic factors of sustained response to interferon alfa therapy in chronic hepatitis C," Hepatology, vol. 22, no. 4, pp. 1050-1056, 1995.

[6] A. Tsubota, K. Chayama, Y. Arase et al., "Factors useful in predicting the response to interferon therapy in chronic hepatitis C," Journal of Gastroenterology and Hepatology, vol. 8, no. 6, pp. 535-539, 1993.

[7] T. Kanda, F. Imazeki, R. Azemoto et al., "Response to peginterferon-alfa $2 \mathrm{~b}$ and ribavirin in japanese patients with chronic hepatitis C genotype 2," Digestive Diseases and Sciences, vol. 56, no. 11, pp. 3335-3342, 2011.

[8] Y. Inoue, N. Hiramatsu, T. Oze et al., "Factors affecting efficacy in patients with genotype 2 chronic hepatitis $\mathrm{C}$ treated by pegylated interferon alpha- $2 \mathrm{~b}$ and ribavirin: reducing drug doses has no impact on rapid and sustained virological responses," Journal of Viral Hepatitis, vol. 17, no. 5, pp. 336-344, 2010.

[9] G. Dusheiko, "Side effects of $\alpha$ interferon in chronic hepatitis C," Hepatology, vol. 26, supplementry S3, pp. 112S-121S, 1997.

[10] T. Azakami, C. N. Hayes, H. Sezaki et al., "Common genetic polymorphism of ITPA gene affects ribavirin-induced anemia and effect of peg-interferon plus ribavirin therapy," Journal of Medical Virology, vol. 83, no. 6, pp. 1048-1057, 2011.

[11] M. Omata, S. Nishiguchi, Y. Ueno et al., "Sofosbuvir plus ribavirin in Japanese patients with chronic genotype $2 \mathrm{HCV}$ infection: an open-label, phase 3 trial," Journal of Viral Hepatitis, vol. 21, no. 11, pp. 762-768, 2014.

[12] D. H. Henry, J. Slim, A. Lamarca, P. Bowers, and G. Leitz, "Natural history of anemia associated with interferon/ribavirin therapy for patients with HIV/HCV coinfection," AIDS Research and Human Retroviruses, vol. 23, no. 1, pp. 1-9, 2007. 


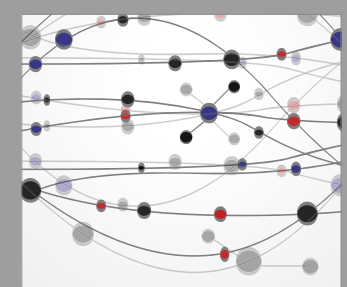

The Scientific World Journal
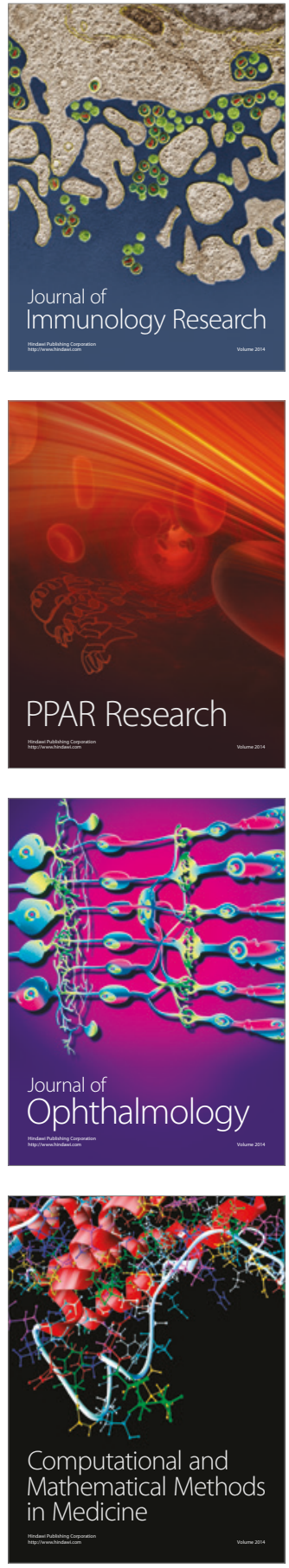

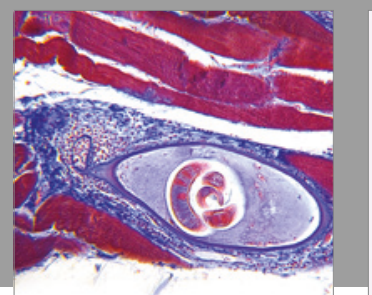

Gastroenterology Research and Practice
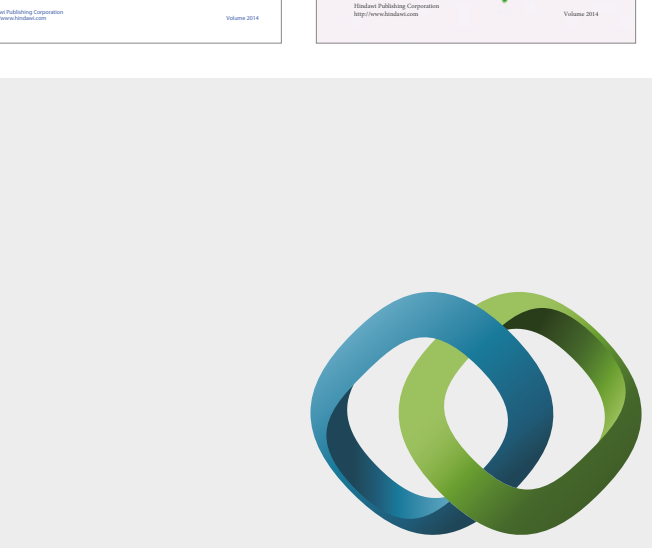

\section{Hindawi}

Submit your manuscripts at

https://www.hindawi.com
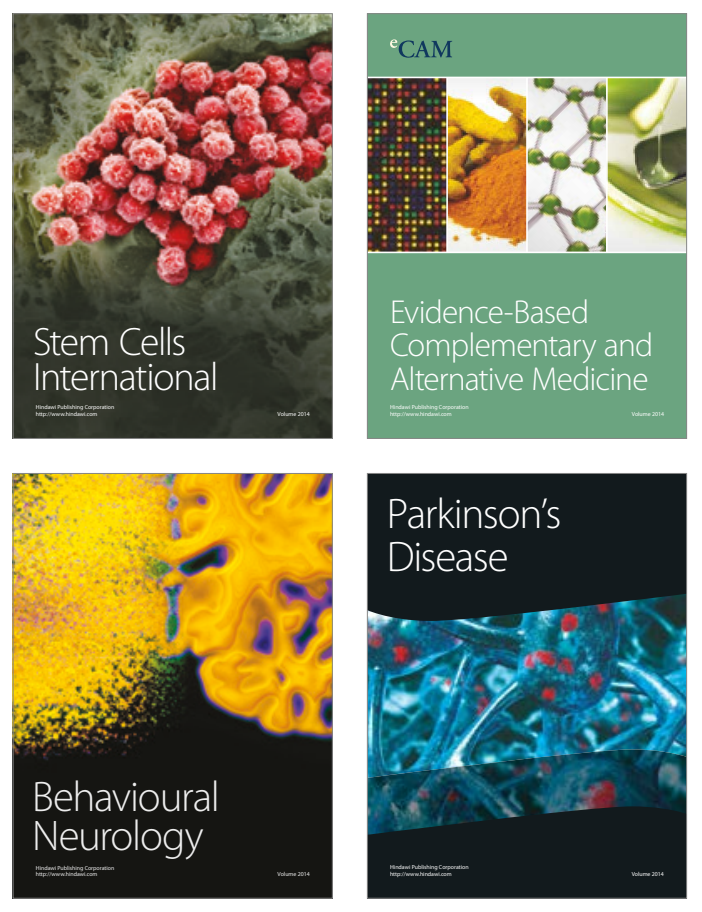
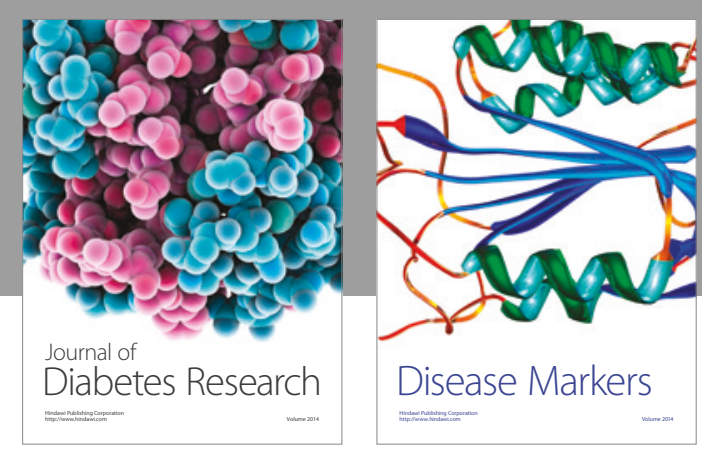

Disease Markers
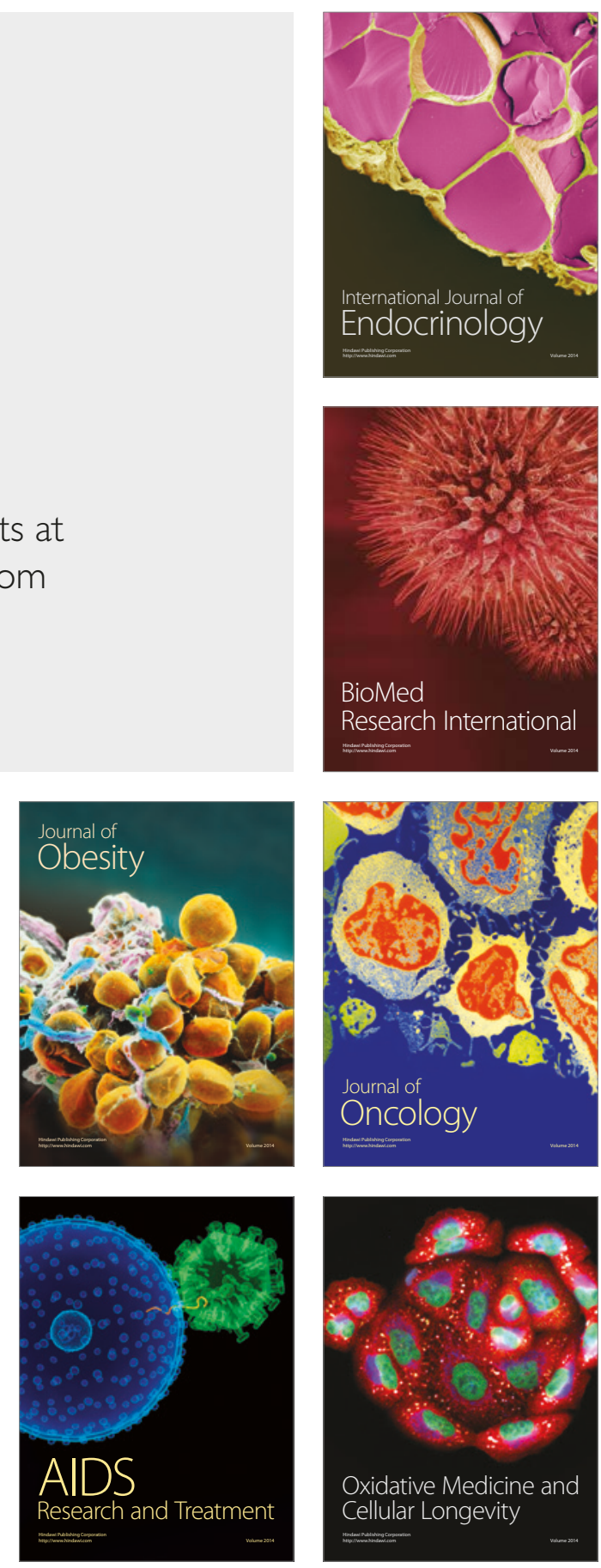